\title{
Framing Effects of Corporate Action on Climate Change: Implications for Consumer Attitudes and Behaviour
}

\author{
Matthew Martin, Jayden Rae, Brooke Struck, Sekoul Krastev, Dan Pilat
}

(Dated: February 18, 2020)

\begin{abstract}
Our study looked at the effects of framing on the public perception of corporate compliance action and government policy, closely mirroring the design of the Federal backstop of the Pan-Canadian Framework. There were three key findings.

First, companies that simply pay their taxes as a penalty for emissions ("merely complying" with the policy) are considered to be less moral, to have less-acceptable practices and to be harming the environment. Alternatively, companies that invest to decrease their carbon footprint ("proactively engaging" with the policy) are more likely to be perceived as acting morally, having acceptable practices and helping the environment.

Secondly, consumers were more willing to bring their business to the proactive companies rather than the merely compliant ones.

Finally, the response of companies also had an effect on citizens' perception of the policy itself. If companies were engaging proactively rather than merely complying, consumers were more likely to view the carbon pricing policy as fair, to support the political party that implemented it, to rate the policy as helping the environment, to rate it as helping Canada's image and reflecting Canadian values, and to rate the policy as helping the economy.

There are key implications for both industry and government to draw from this research. For industry, communicating proactive policy engagement improves public image and increases consumer support. For the government, communicating to industry the positive benefits - environmental, economic and social - of proactive engagement could increase overall private-sector engagement and thereby improve the public's perception of the policy itself. Overall, this suggests that compliance with and support for carbon pricing policies is a promising opportunity for the private sector to communicate their environmental and social commitments.
\end{abstract}

\section{INTRODUCTION}

Concern about climate change, both domestically and abroad, has made carbon pricing one of the most salient policy topics in Canada. The Pan-Canadian Framework on Clean Growth and Climate Change was implemented as a measure intended to reduce greenhouse gas (GHG) emissions. Provinces are free to develop their own policies, but in provinces where no policy is developed (or the policy is deemed non-compliant with the federal Framework), the "backstop" component of the framework kicks in; in this case, the federal government applies a carbon tax and sends a rebate to Canadian consumers to redistribute carbon tax revenues within the province in which they were collected. This study is inspired by the federal backstop and seeks to understand how framing industry engagement with the policy affects consumer evaluations of individual companies and the policy itself.

From a policy perspective, carbon pricing is an effective way to reduce greenhouse gas emissions at an economy-wide level (Nordhaus 2011; Sterner and KÃúhlin 2019). GHGs, like other forms of air pollution, are a negative environmental externality. Pricing an externality is a mechanism to internalize the negative cost and consequently reduce the supply of the harmful good (Nordhaus 2011). Raising the market price of carbon therefore increases the incentives to reduce carbon emissions by offering producers economic benefits for using low-carbon energy sources and technologies (Beugin et al. 2019; Rivers 2015).

In this study we refer to companies that are actively engaging with the policy by investing their tax savings into emissions-reducing activities as "Proactive" companies. We refer to companies that are merely complying with their obligations under the federal carbon pricing policy and paying the carbon-tax as "Compliant" companies.

In this study we are specifically interested in consumer responses to different framings of industry engagement with carbon pricing policy. Frames can be considered as "subtle alterations in the statement or presentation of judgement and choice problems" (Iyengar 1991, p. 11). Framing triggers individuals' unconscious perception of information by the way in which information is provided - in this instance, information about policy compliance.

Drawing on framing theory, this study has two main objectives. First, we examine how framing industry-level involvement in policy through the language of proactive engagement versus compliance influences consumer evaluations of individual company's morality, practices, environmental commitments, and suitability for business relationships.

Second, following from the first objective, we assess how consumer evaluations of companies relate to their assessment of carbon pricing policies. Research by the EcoFiscal Commission has found that despite an over- 
whelming level of Canadian concern for the impacts of climate change, there are mixed levels of public support for carbon pricing policies. A poll of 2259 Canadians on carbon pricing found that just under half (46\%) say it's a good idea, compared to $22 \%$ who say it's a poor idea. This leaves $33 \%$ of Canadian's somewhere in the middle, considering carbon pricing to be an "acceptable idea" (Beugin et al. 2019). The second objective of the study, therefore, is to assess how industry participation in carbon pricing initiatives would influence public perception of the policy itself, especially with so many Canadians not committed to a firm position on the issue (and that arguments often mobilized against carbon pricing focus on the potential for negative impacts on business).

Other research suggests that industry support/engagement with environmental policies plays a role in overall public acceptance (Arora and Gangopadhyay 1995; Wu 2009). This component of the study builds on these findings. We define "public support" in this context along six dimensions: the extent to which the carbon pricing policy is seen as fair, extending political party support, helping the environment, helping Canada's image, reflecting Canadian values, and helping the economy.

$=$ Our findings suggest that framing plays a significant role that is relevant for both industry actors as well as policy-makers. We find that companies that simply pay their taxes as a penalty for emissions ("merely complying" with the policy) are considered to be less moral, to have less-acceptable practices and to be harming the environment. Alternatively, companies that invest to decrease their carbon footprint ("proactively engaging" with the policy) are more likely to be perceived as acting morally, having acceptable practices and helping the environment. Additionally, consumers were more willing to bring their business to the proactive companies rather than the merely compliant ones.

These preliminary findings are consistent with previous research demonstrating that policy framing has significant effects on consumer attitudes and behaviours. These findings are relevant to all actors working to increase public engagement and support for carbon-mitigating activities.

\section{RESEARCH QUESTION AND HYPOTHESIS}

This study sought to examine two ways in which the framing of compliance with carbon pricing could influence consumer attitudes and behaviour in respect to industry and the pricing policy itself. First, we examine the framing effect of industry involvement on consumer evaluations of individual companies; specifically, our interest was to determine how consumers might respond differently to companies based on how those companies engaged with the carbon tax. The framing is based on policy models, including that of British Columbia, where businesses are given tax breaks in exchange for adopting emissions reducing-activities and technologies (Beugin et al. 2019). We wanted to investigate whether consumers judge companies positively if they take advantage of these tax breaks by reinvesting into greenhouse gas reducing activities, rather than simply paying the tax but continuing "business as usual." We expect that framing a company's actions as "environmentally-friendly investments" will increase positive perceptions of the company.

Second, we assess how industry commitment to carbon pricing policy has wider effects on the public's image of the policy. This research question bridges the consequences of framing between the public and private sectors. We expect that when companies are framed as proactively engaging with carbon pricing it will increase positive public attitudes towards the policy more generally.

\section{METHOD}

A sample of 118 Canadians was recruited using the online recruitment software Mechanical Turk. The participants in this study were the same as ones included in another study on the topic, who completed the task of this experiment after the ones in Martin et al. (2019). Their participation took approximately 15 minutes to complete.

Participants were randomly assigned to read one of two hypothetical scenarios about a national carbon tax policy and industry engagement. Afterwards, all participants answered the same questions related to the scenario and then filled out a series of demographics questionnaires, including questions about their age, gender, income, education, province of residence, marital status and living situation. They were also asked about their political attitudes and beliefs about several issues, including climate change (see Figure 1 for a layout of the experimental design).

In the scenario, each participant was supplied with the following statement: "Suppose that national carbon pricing legislation gives businesses a choice in how they contribute to reducing carbon emissions. They can either pay a fee proportional to their carbon usage, or they can choose to invest the same amount in carbon-reducing practices." The participant was then given one of two potential scenarios wherein "One particular company, Standard Inc., decides to" a) "pay a fee related to their carbon usage instead of investing in carbon-reducing practices" or to b) "invest in carbon-reducing practices instead of paying a fee". Participants then rated how much they agreed with a series of 11 statements on a five-point likert scale $(1=$ strongly disagree, $5=$ strongly agree $)$ about their evaluation of the company's behaviour and the tax policy (see Table I). 


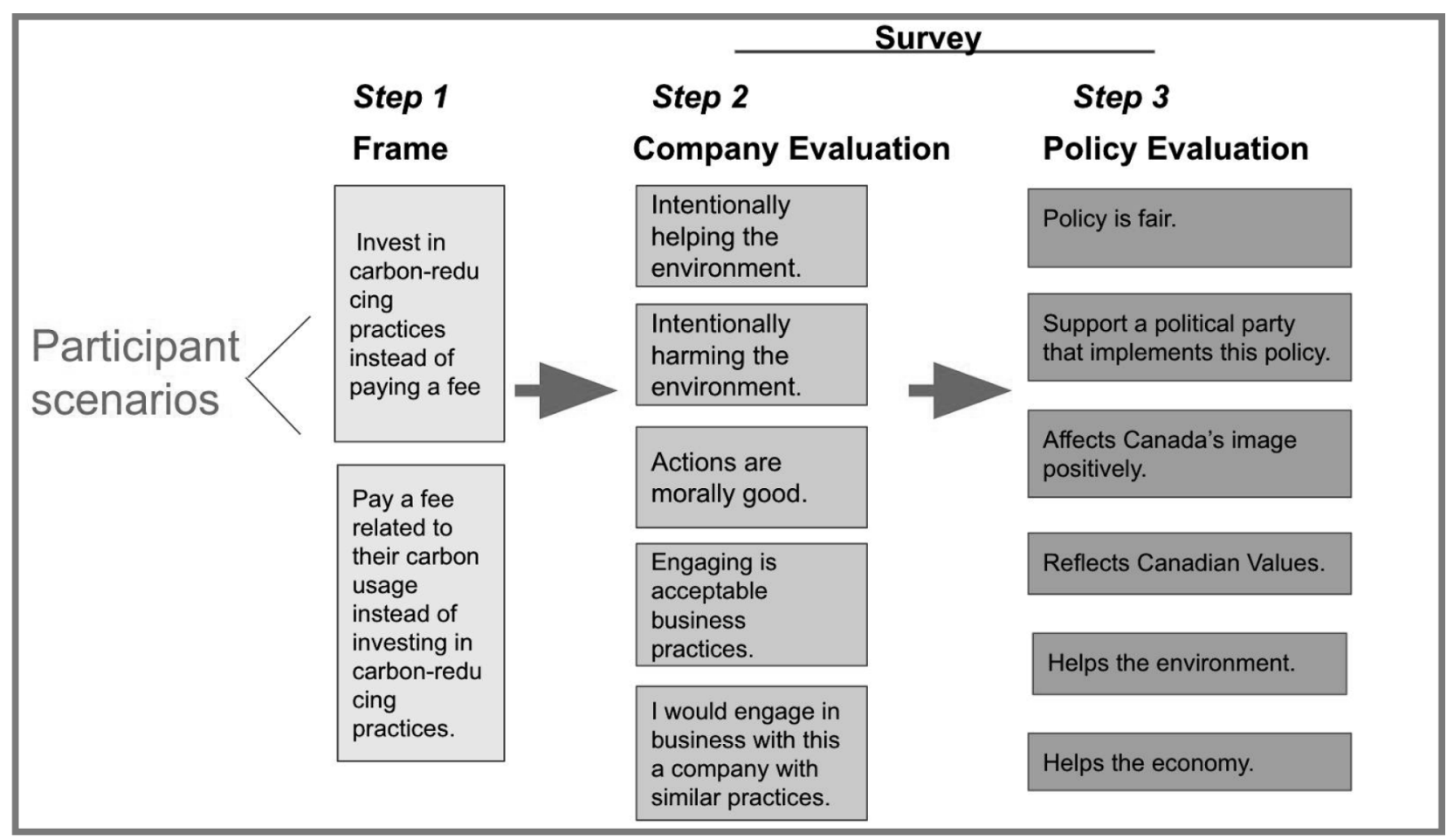

Figure 1: Methodology: frame, company evaluation and policy evaluation

\section{RESULTS}

For the first research question addressing the company evaluation, the data were analyzed using a one-way MANOVA with the five dependent variables for evaluation. The results revealed a significant effect of condition with a large effect size, Wilks'Lambda $=0.58$, $F(5,112)=16.05, p<.001, \eta_{\text {part }}^{2}=0.42$. Follow-up univariate analyses using Bonferroni correction for multiple comparisons revealed that all 5 of the dependent variables were affected by the condition (Table II), all indicating that participants had more positive evaluations towards the company that invested in carbon-reducing practices compared to the one that merely complied with the carbon tax (see Figure 2).

For the second research question related to the policy evaluation, a one-way MANOVA with six dependent variables was conducted. The analysis revealed an effect of condition with a large effect size, Wilks'Lambda $=0.77, F(6,111)=5.90, p<.001, \eta_{\text {part }}^{2}=0.23$. Followup univariate tests on each of the dependent variables using Bonferroni correction for multiple tests all revealed significant effects (Table III), all indicating that participants who evaluated the policy of investing in carbonreducing emissions had more positive attitudes towards it compared to participants who evaluated the policy of mere compliance (see Figure 3).

\section{DISCUSSION}

The first finding reveals that participants were more likely to describe the proactive company that invested in carbon-reducing activities as helping the environment, not hurting the environment, morally good, and engaging in acceptable business practices, in comparison to the merely compliant company that simply paid the carbonbased fee. Additionally, respondents were more likely to do business with the proactive companies. These results indicate that Canadians react positively to company actions in green investments, rather than mere compliance with carbon-based fees. This finding suggests companies can improve their public image by communicating their proactive environmental engagement to the public.

A potential explanation for these findings is that consumers are responsive to green and socially responsible behaviour and marketing, which can explain the positive image of the company and consumer's willingness to do business with them. Research by Bennett et al. (2016) on electric vehicles found that image-related factors for environmental responsibility "can override more rational utility-based calculations" (p.66).

This relates closely to green consumer theory which posits that firms may respond proactively to policy that appeals to environmentally conscious consumers, who are willing to pay more for green products or redirect their demand toward environmentally friendly firms (Arora and Gangopadhyay 1995). There is some em- 
pirical evidence to support this theory. For example, Rivera (2002) found that hotels that participated in the Costa Rican Certification for Sustainable Tourism program and showed certified superior environmental performance were able to obtain a price premium and higher sales volume. In other studies, 'Arora and Cason (1996) and Khanna and Damon (1999) found that firms in industries with greater consumer contact are more likely to participate in the EPA's voluntary 33/50 Program.

In the policy evaluation component of the study, the dependent variables showed that if the company invested proactively in emissions-reducing activities, participants were more likely to rate the carbon-pricing policy as fair, support the political party that implemented it, rate the policy as helping the environment, helping Canada's image, reflecting Canadian values, and helping the economy. Thus, the response of industry had an important influence on the reactions of Canadians to a tax policy that directly incentivises companies to reduce greenhouse gas emissions.

This finding suggests that the public takes signals from how corporations respond to carbon taxes. If the actions of corporations are following the spirit of an environmental policy, it improves the overall public image of the policy. Other research shows that when the public has trust in the specific actors engaged in environmental policy there is public support for the policy. For example, in the domain of forestry management, a high confidence in forestry agencies, experts and industry has been positively associated with acceptance of forest management policies and their implied risks (St-Laurent et al. 2018). Following from this example, Olsen and Shindler (2010) explain that trust in forestry agencies and land managers is particularly important when the public lacks familiarity with, but values the outcomes of, environmental practices. This explanation is relevant to climate change as well because most members of the public are not informed on the science behind the issue or the mechanisms to reduce emissions, but are nonetheless concerned about addressing it. If members of the public develop trust in proactive companies, they will increase their support for climate policy more widely. This relationship is important to policymakers who are framing and articulating policy aimed at industry-level behavioural and attitudinal change. Communicating to industry leaders the business benefits of proactive carbon-reduction behaviour could be an incentive to increase ambition and implement tangible actions.

Several caveats should be kept in mind when considering these results. First, the sample population is more liberal and higher income than the Canadian population at large. These observations align with the characteristics of typical Mechanical Turk participants, who tend to be younger (about 30 years old), more educated, underemployed, less religious, and more liberal than the general population (Berinsky et al. 2012; Paolacci and
Chandler 2014; Shapiro et al. 2013). Second, the sample size for this study was small. Accordingly, the findings may not be representative of patterns within the wider Canadian population. We suggest that future research should increase the sample size and use stratified random sampling to ensure representativeness of the Canadian population as well as to enable disaggregation to be able to understand subgroups within the population, such as differences across provinces or income groups.

An additional caveat is that this study did not specify the industry in which the hypothetical company was operating. The company was also given the generic name of "Standard Inc." Accordingly, we are not able to determine if the type of industry (i.e steel, oil or gas production, professional services) or the existing reputation of the company (associated with its name and public image) would have an impact on consumer responses to the company's engagement with the carbon-pricing policy.

Finally, regarding intentions to do business with a given company, the study relied on self-reported intentions about behaviour rather than direct measurements of that behaviour itself; accordingly, this study should be interpreted as elucidating the effects of framing and policy design on attitudes rather than on behaviours. However, other research has found that the theory of planned behaviour (TPB) is very useful to explain individuals' behaviours and intentions in a variety of settings (Godin and Kok 1996, Godin et al. 2008); a systematic review of social theories applying the methodology concludes that the TPB is very useful to explain healthcare professionals' behaviours and intentions (Godin et al. 2008). This research suggests that the results obtained here are likely to be informative about behavioural outcomes, even while noting that a direct measurement of those outcomes would provide more robust evidence than self-reported attitudes do.

In summary, there are key implications for actors engaged in carbon policy at the industry and government level. For industry, these findings elucidate that proactive engagement with carbon policy in the form of green investments to reduce emissions has an important business value. Proactive engagement improves consumer attitudes towards the company and also results in behavioural change by shifting their preferences for which companies to engage in business with.

For policymakers, there are two key lessons. First, government should communicate to industry leaders the wider benefits of actively engaging with carbon pricing policy in order to promote active investments in emissions-reducing activities over mere payment of the carbon tax. This has the potential to encourage more substantial economy-wide carbon emission reductions. Secondly, policymakers should consider how framing industry involvement in carbon pricing improves public attitudes towards the policy more generally. At a time when many Canadians are concerned about climate 
change but are simultaneously unsure about carbon pricing as a solution (Beugin et al. 2019), simple framing could improve public perceptions.

In summary, this research supports other evidence demonstrating that the public takes signals from how corporations respond to carbon taxes. If the actions of corporations are following the spirit of the environmental policy, it improves the overall public image of the company and the policy itself. Advocates of carbon pricing policy would be wise to consider how to broaden and strengthen public support through framing and communicating industry engagement.

Prof Andersen and Mikael Skou. EuropeâĂŹs experience with carbon-energy taxation. SAPI EN. S. Surveys and Perspectives Integrating Environment and Society, (3.2), 2010. URL http: // journals.openedition.org/sapiens/1072.

Seema Arora and Timothy N Cason. Why do firms volunteer to exceed environmental regulations? understanding participation in epa's 33/50 program. Land economics, pages 413 432, 1996. URL https : //doi.org/10.2307/3146906.

Seema Arora and Shubhashis Gangopadhyay. Toward a theoretical model of voluntary overcompliance. Journal of economic behavior \&S organization, 28(3):289-309, 1995. URL https : / /doi.org/10.1016/0167-2681 (95)00037- 2.

Roger Bennett, Rita Kottasz, and Stephen Shaw. Factors potentially affecting the successful promotion of electric vehicles. Journal of Social Marketing, 6(1):62-82, 2016. URL https : //doi.org/10.1108/JSOCM-08-2015-0059.

Adam J Berinsky, Gregory A Huber, and Gabriel S Lenz. Evaluating online labor markets for experimental research: Amazon. com's mechanical turk. Political analysis, 20(3):351368, 2012. URL https://doi.org/10.1093/pan/mpr057.

Dale Beugin, Frank Brendan, Hodgson Glen, Lipsey Richard, Olewiler Nancy, and Chris Ragan. Clearing the Air: How Carbon Pricing Helps Canada Fight Climate Change - by the Ecofiscal Commission. CanadaâĂŹs Ecofiscal Commission, 2019. URL https://ecofiscal.ca/carbon-pricing-works/.

Dennis Chong and James N Druckman. Framing theory. Annu. Rev. Polit. Sci., 10(1):103-126, 2007. URL https : //doi.org/10.1146/annurev.polisci.10.072805.103054.

Gaston Godin and Gerjo Kok. The theory of planned behavior: a review of its applications to health-related behaviors. American journal of health promotion, 11(2):87-98, 1996. URL https : //doi.org/10.4278/0890-1171-11.2.87.
Shanto Iyengar. Is anyone responsible? how television frames political issues. 1991. URL https : / / doi.org/10.7208/ chicago/9780226388533.001.0001.

Madhu Khanna and Lisa A Damon. Epa's voluntary 33/50 program: Impact on toxic releases and economic performance of firms. Journal of environmental economics and management, 37(1):1-25, 1999. URL https://doi.org/10.1006/ jeem.1998.1057.

William D Nordhaus. The architecture of climate economics: Designing a global agreement on global warming. Bulletin of the Atomic Scientists, 67(1):9-18, 2011. URL https : // doi.org/10.1177/0096340210392964.

Gabriele Paolacci and Jesse Chandler. Inside the turk: Understanding mechanical turk as a participant pool. Current Directions in Psychological Science, 23(3):184-188, 2014. URL https : //doi.org/10.1177/0963721414531598.

Lyn E Pleger, Philipp Lutz, and Fritz Sager. Public acceptance of incentive-based spatial planning policies: A framing experiment. Land use policy, 73:225-238, 2018. URL https://doi.org/10.1016/j.landusepol.2018.01.022.

Jorge Rivera. Assessing a voluntary environmental initiative in the developing world: The costa rican certification for sustainable tourism. Policy Sciences, 35(4):333-360, 2002. URL https : //doi.org/10.1023/A : 1021371011105.

Nicholas Rivers. The case for a carbon tax in canada. Available at SSRN 2640599, 2015. URL https://doi.org/ 10.2139/ssrn.2640599.

Danielle N Shapiro, Jesse Chandler, and Pam A Mueller. Using mechanical turk to study clinical populations. Clinical Psychological Science, 1(2):213-220, 2013. URL https : //doi.org/10.1177/2167702612469015.

Guillaume Peterson St-Laurent, Shannon Hagerman, Robert Kozak, and George Hoberg. Public perceptions about climate change mitigation in british columbia's forest sector. PloS one, 13(4):e0195999, 2018. URL https : //doi.org/10.1371/ journal.pone.0195999.

Thomas Sterner and Gunnar KÃúhlin. Pricing carbon: The challenges. researchgate. Accessed January 16 2019. URL https://www.researchgate.net/publication/ 299494867_Pricing_carbon_The_challenges.

JunJie Wu. Environmental compliance: the good, the bad, and the super green. Journal of Environmental Management, 90(11):3363-3381, 2009. URL https ://doi.org/10.1016/ j.jenvman.2009.05.017.

Andreas Ziegler. Political orientation, environmental values, and climate change beliefs and attitudes: An empirical cross country analysis. Energy Economics, 63:144-153, 2017. URL https : //doi.org/10.1016/j.eneco.2017.01.022. 


\section{APPENDIX}

Table I: Evaluation Statements

\begin{tabular}{|l|}
\hline Policy Evaluation Questions \\
\hline 1) I think this is a fair policy. \\
\hline 2) I would support a political party that implements this policy. \\
\hline 3) I think this policy will help the environment. \\
\hline 4) I think this policy affects the image of Canada positively. \\
\hline 5) I think this policy reflects Canadian values. \\
\hline 6) I think this policy helps the economy. \\
\hline 7) I think this policy helps my personal finances. ${ }^{\text {a }}$ \\
\hline Company Evaluation Questions \\
\hline 1) Standard Inc. are intentionally helping the environment. \\
\hline 2) Standard Inc. are intentionally hurting the environment. \\
\hline 3) Standard Inc. are morally good. \\
\hline 4) Standard Inc. are engaging in acceptable business practices. \\
\hline 5) I would be likely to engage in business with a company like Standard Inc. \\
\hline
\end{tabular}

Table II: Univariate analyses on effects of business tax compliance on evaluation of the company

\begin{tabular}{|l|c|c|c|c|c|c|c|c|c|}
\hline Dependent Variable & $M_{\text {dif(invest-fee) }}$ & $S E_{\text {dif }}$ & $S S$ & $d f_{\text {cond }}$ & $d f_{\text {error }}$ & $M S$ & $F$ & $p$ & $\eta_{\text {part }}^{2}$ \\
\hline Help environment & 1.569 & 0.192 & 72.392 & 1 & 116 & 72.392 & 67.018 & $<.001$ & .366 \\
\hline Hurt environment & -.982 & 0.196 & 28.349 & 1 & 116 & 28.349 & 25.056 & $<.001$ & .178 \\
\hline Morally good & .853 & 0.15 & 21.415 & 1 & 116 & 21.415 & 32.493 & $<.001$ & .219 \\
\hline Acceptable business practice & .716 & 0.149 & 15.085 & 1 & 116 & 15.085 & 23.035 & $<.001$ & .166 \\
\hline Engage in business & .944 & 0.166 & 26.195 & 1 & 116 & 26.195 & 32.438 & $<.001$ & .219 \\
\hline
\end{tabular}

Table III: Univariate analyses of effects of company engagement with policy evaluation

\begin{tabular}{|l|c|c|c|c|c|c|c|c|c|}
\hline Dependent Variable & $M_{\text {dif(invest-fee })}$ & $S E_{\text {dif }}$ & $S S$ & $d f_{\text {cond }}$ & $d f_{\text {error }}$ & $M S$ & $F$ & $p$ & $\eta_{\text {part }}^{2}$ \\
\hline Fair policy & .823 & 0.182 & 19.937 & 1 & 116 & 19.937 & 20.551 & $<.001$ & .150 \\
\hline Support party & .896 & 0.206 & 23.608 & 1 & 116 & 23.608 & 18.987 & $<.001$ & .141 \\
\hline Policy helps environment & .843 & 0.204 & 20.897 & 1 & 116 & 20.897 & 17.064 & $<.001$ & .128 \\
\hline Canada's image & .891 & 0.175 & 23.366 & 1 & 116 & 23.366 & 25.787 & $<.001$ & .182 \\
\hline Canadian values & .880 & 0.159 & 22.795 & 1 & 116 & 22.795 & 30.545 & $<.001$ & .208 \\
\hline Helps economy & .688 & 0.177 & 13.942 & 1 & 1116 & 13.942 & 15.156 & $<.001$ & .116 \\
\hline
\end{tabular}




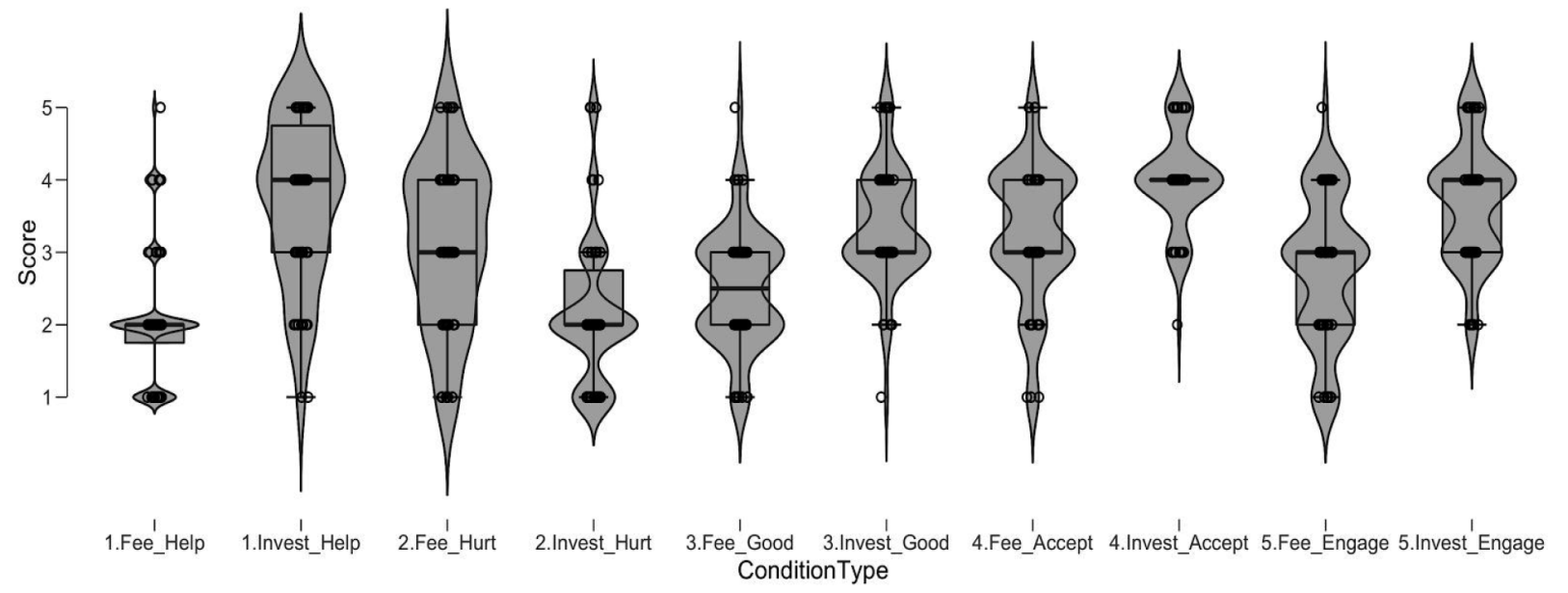

Figure 2: Ratings of each dependent variable regarding business practices, split by condition.

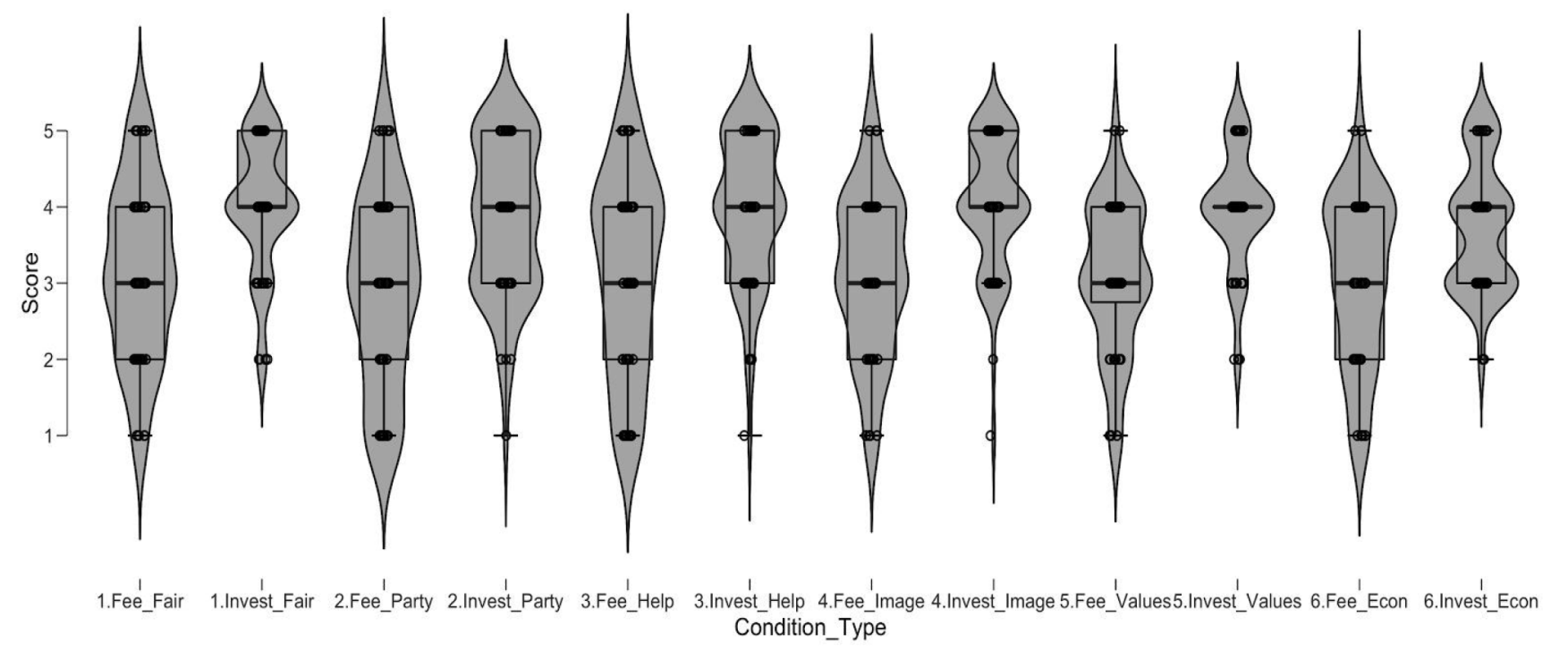

Figure 3: Ratings of each dependent variable regarding policy, split by condition. 
Table IV: Demographic Information of Participants

\begin{tabular}{|c|c|c|}
\hline \multicolumn{3}{|c|}{ Gender } \\
\hline & Frequency & Percent \\
\hline Female & 44 & 37.3 \\
\hline Male & 74 & 62.7 \\
\hline Total & 118 & 100 \\
\hline \multicolumn{3}{|c|}{ Marital status } \\
\hline & Frequency & Percent \\
\hline Common Law & 14 & 11.9 \\
\hline Divorced & 4 & 3.4 \\
\hline Married & 38 & 32.2 \\
\hline Single & 61 & 51.7 \\
\hline Widowed & 1 & 0.8 \\
\hline Total & 118 & 100 \\
\hline \multicolumn{3}{|c|}{ Age } \\
\hline & Frequency & Percent \\
\hline $18-20$ & 12 & 10.2 \\
\hline $21-30$ & 51 & 43.2 \\
\hline $31-40$ & 34 & 28.8 \\
\hline $41-50$ & 13 & 11 \\
\hline $51-60$ & 5 & 4.2 \\
\hline $61-70$ & 3 & 2.5 \\
\hline Total & 118 & 100 \\
\hline \multicolumn{3}{|c|}{ Income $(\mathrm{CAD} \$)$} \\
\hline & Frequency & Percent \\
\hline$<10000 \mathrm{CAD}$ & 5 & 4.2 \\
\hline $10000-20000$ & 7 & 5.9 \\
\hline $20000-30000$ & 12 & 10.2 \\
\hline $30000-40000$ & 15 & 12.7 \\
\hline $40000-50000$ & 7 & 5.9 \\
\hline $50000-60000$ & 8 & 6.8 \\
\hline $60000-70000$ & 11 & 9.3 \\
\hline $70000+$ & 39 & 33.1 \\
\hline Not Sure / Prefer not to answer & 14 & 11.9 \\
\hline Total & 118 & 100 \\
\hline
\end{tabular}

